\title{
A Role of the Heme Degradation Pathway in Shaping Prostate Inflammatory Responses and Lipid Metabolism
}

Lisa Vikström Lilljebjörn, * Eva Csizmadia, ${ }^{*}$ Andreas Hedblom, ${ }^{*}$ Giacomo Canesin, ${ }^{*}$ Alireza Kalbasi, ${ }^{*}$ Mailin Li, ${ }^{*}$ Farah Kramer, ${ }^{\dagger}$ Karin E. Bornfeldt, ${ }^{\dagger \ddagger}$ and Barbara Wegiel ${ }^{\star \S}$

From the Division of Surgical Oncology, * Department of Surgery, Beth Israel Deaconess Medical Center, Harvard Medical School, Boston, Massachusetts; the Department of Medicine, ${ }^{\dagger}$ Division of Metabolism, Endocrinology, and Nutrition, UW Medicine Diabetes Institute, Seattle, Washington; and the Department of Pathology, ${ }^{\ddagger}$ University of Washington School of Medicine, Seattle, Washington; and the Cancer Research Institute, ${ }^{\S}$ Boston, Massachusetts

Accepted for publication December 5, 2019.

Address correspondence to Barbara Wegiel, Ph.D., Department of Surgery, Harvard Medical School, Beth Israel Deaconess Medical Center, 3 Blackfan Circle CLS \#613, Boston, MA 02215. E-mail: bwegiel@bidmc.harvard.edu.

\begin{abstract}
The molecular mechanisms of prostate inflammation are unclear. We hypothesized that heme oxygenase 1 (HMOX1; H0-1), an enzyme responsible for degradation of heme to carbon monoxide, bilirubin, and iron, is an important regulator of inflammation and epithelial responses in the prostate. Injection of non-uropathogenic Escherichia coli (MG1655 strain) or phosphate-buffered saline into the urethra of mice led to increased numbers of $\mathrm{CD}_{4} 5^{+}$leukocytes and mitotic markers (phosphorylated histone $\mathrm{H}_{3}$ and phosphorylated ERK1/2) in the prostate glands. Leukocyte infiltration was elevated in the prostates harvested from mice lacking $\mathrm{H} 0-1$ in myeloid compartment. Conversely, exogenous carbon monoxide (250 ppm) increased IL-1 $\beta$ levels and suppressed cell proliferation in the prostates. Carbon monoxide did not affect the number of infiltrating $\mathrm{CD}_{4} 5^{+}$cells in the prostates of $E$. coli- or phosphate-buffered saline-treated mice. Interestingly, immunomodulatory effects of $\mathrm{HO}-1$ and/or carbon monoxide correlated with early induction of the long-chain acyl-CoA synthetase 1 (ACSL1). ACSL1 levels were elevated in response to $E$. coli treatment, and macrophage-expressed ACSL1 was in part required for controlling of IL-1 $\beta$ expression and prostate cancer cell colony growth in soft agar. These results suggest that $\mathrm{H} 0-1$ and/or carbon monoxide might play a distinctive role in modulating prostate inflammation, cell proliferation, and IL-1 $\beta$ levels in part via an ACSL1-mediated pathway. (Am J Pathol 2020, 190: 830-843; https://doi.org/10.1016/j.ajpath.2019.12.008)
\end{abstract}

Inflammation in the prostate is a common urogenital tract condition in men that leads to pain. ${ }^{1,2}$ It has been postulated that prostate inflammation also leads to an increased risk of prostate cancer; however, studies have reached conflicting results. ${ }^{3,4}$ Ninety-five percent of prostatitis cases involve chronic prostatitis or chronic pelvic pain syndrome in which bacteria cannot be detected but inflammatory cells are present. In some cases, no inflammatory component can be detected. Five percent of men with chronic bacterial prostatitis present with no detectable bacteria in the prostate, and $50 \%$ lack leukocytosis in the prostate. ${ }^{5}$ Fecal Escherichia coli, bacteria causing sexually transmitted diseases or uropathogenic bacteria, are among the pathogens found to be associated with urogenital tract infection and linked to prostatitis. E. coli was previously detected in prostate tissues $^{6,7}$; however, these studies are limited by the number of patients without comprehensive data confirming this observation.

Inflammation in the prostate can be driven by activation of residential macrophages and/or infiltration of leukocytes in response to pathogen-associated molecular patterns or danger-associated molecular patterns released from bacteria or damaged cells, respectively. ${ }^{8}$ Chronic inflammation is

Supported in part by NIH grants R01 DK104714 (B.W.), R21 CA169904 (B.W.), and P01HL092969 (K.E.B.); and Department of Surgery, Beth Israel Deaconess Medical Center start-up funds (B.W.).

Disclosures: None declared.

Portions of this article are taken from Dr. Lilljebjörn's master's thesis submitted at Lund University, Malmo, Sweden (2015). 
propagated by continuous release of reactive oxygen species and proinflammatory mediators from immune cells and may lead to damage of the prostate tissue. ${ }^{9}$ Further, unresolved inflammatory response is linked to gastric, colon, and prostate cancer. ${ }^{10}$ Elkahwaji et $\mathrm{al}^{11}$ found that chronic bacterial infection of the mouse prostate led to the development of prostatic intraepithelial neoplasia lesions after induction of prostatitis by intraurethral injection of $E$. coli into $\mathrm{C} 3 \mathrm{H} / \mathrm{HeOuJ}$ mice. In this model, infiltration of leukocytes into the prostate stroma was associated with increased epithelial DNA damage and proliferation and lower expression of the tumor suppressors, PTEN and p27 $7^{\text {Kip } 1.11}$ Furthermore, intraurethral injection of bacterial lipopolysaccharide led to hyperplasia, inflammation, and bleeding in the prostate. ${ }^{12}$

Degradation of heme is catalyzed by heme oxygenase 1 (HO-1) and generates biliverdin, ferrous iron, and carbon monoxide. ${ }^{13,14} \mathrm{HO}-1$ and $\mathrm{CO}$ have major immunomodulatory properties. ${ }^{15-17}$ Recently, we found that carbon monoxide treatment after infection potentiates bacterial clearance $^{18}$ and amplifies proinflammatory responses in macrophages in a mouse model of sepsis in part via Nalp3 inflammasome-dependent release of IL- $1 \beta .{ }^{19}$ This mechanism involves a direct effect of carbon monoxide on bacteria facilitating active release of ATP from bacteria. Extracellular ATP, acting as a danger-associated molecular pattern, binds to the macrophage-expressed $\mathrm{P}_{2} \mathrm{X}_{7}$ receptor, ${ }^{19}$ activating the Nalp3 inflammasome via changes in intracellular potassium levels to drive IL- $1 \beta$ expression. ${ }^{20-23}$ Monocytederived IL-1 $\beta$ has antiproliferative properties in prostate cancer cells and blocks androgen receptor-dependent expression of-prostate-specific antigen. ${ }^{24}$ In contrast, others found that IL- $1 \beta$ promotes bone marrow metastases and neuroendocrine phenotype of prostate cancer cells. ${ }^{25} \mathrm{IL}-$ 1 receptor 1 knockout mice have low expansion of c$\mathrm{kit}^{+}$progenitors in the inflamed prostate linking abnormal proliferation with IL-1 signaling. ${ }^{26}$ Previous data from our group indicate a strong induction of HO-1 in macrophages after infection with $E$. coli or Enterococcus faecalis and the importance of HO-1 in the generation of IL- $1 \beta .{ }^{19}$

Long-chain acyl-CoA synthetase 1 (ACSL1), one of five isoforms of an enzyme family that activate fatty acids by coupling them to coenzyme A, has been previously reported to be upregulated in tumors ${ }^{27}$ and is induced during bacterial infection via a toll-like receptor 4-dependent mechanism. ACSL1 mediates phospholipid turnover in lipopolysaccharide-stimulated macrophages ${ }^{28}$ among other effects. ${ }^{29}$ ACSL1 converts free long-chain fatty acids into fatty acyl-CoA esters, thereby playing a key role in lipid biosynthesis and $\beta$-oxidation. Conditional deletion of ACSL1 in myeloid cells prevents macrophage accumulation in the artery wall in diabetic mice, indicating a role for ACSL1 in inflammatory responses. ${ }^{29}$

Because ACSL1 and HO-1 regulate metabolic stress and immune responses, we hypothesized that HO-1 and/or carbon monoxide crosstalks with ACSL1 signaling in macrophages during inflammatory responses in the prostate. We report here that ACSL1 is a potential target of the heme degradation pathway in macrophages.

\section{Materials and Methods}

\section{Bacteria Culture}

Nonuropathogenic Escherichia coli MG1655, originally acquired from the Keio library, was provided by Bernard Strauss (Massachusetts Institute of Technology, Cambridge, MA). This E. coli strain has been described previously. ${ }^{19}$ This strain of bacteria was used in bacterial infection experiments in vitro and in vivo. Bacteria were inoculated in Luria broth medium from a frozen aliquot obtained from a single colony. Fresh Luria broth was inoculated with a $1 \mathrm{~mL}$ aliquot of the overnight culture and subcultured at $37^{\circ} \mathrm{C}$ until bacteria suspensions reached an OD measured at 600 $\mathrm{nm}$ of 0.45 . Cells were pelleted at $3220 \times g(5$ minutes $)$ and resuspended in sterile phosphate-buffered saline (PBS). Serial dilutions of stock suspension (1:1000 to $\left.1: 10^{9}\right)$ were plated in duplicates on Luria broth agar and incubated at $37^{\circ} \mathrm{C}$ in the o/n culture. Colony counts were averaged and used to estimate the concentration of bacteria in the prepared stock with OD measured at $600 \mathrm{~nm}$ of 0.45 . Appropriate volumes of the bacteria dilutions were used to prepare injections for infection in vivo or for in vitro treatments.

\section{Animals}

C57BL/6 male mice (Jackson Laboratories, Bar Harbor, ME) 7 to 10 weeks of age weighing 20 to $25 \mathrm{~g}$ were used (after at least 3 days of acclimatization) for in vivo prostatitis model, and both sexes of mice were used for bone marrow isolation. Acsll ${ }^{f f f}:$ LysM-Cre and Acsll ${ }^{w t / w t}$-Cre control mice, also with the C57BL/6 background, were previously described. ${ }^{29}$ To establish models of pathogen-induced and sterile prostatitis, intraurethral instillation of $E$. coli MG1655 $\left(2 \times 10^{8}\right.$ CFU per animal) or PBS $(n=3$ to 6 per group) was performed. Injections were performed using a 30 -gauge syringe connected to lubricated polyvinyl tubing $(0.8 \mathrm{~mm}$ across $)$ inserted into the urinary bladder via the urethra. The procedures were performed with the mice under 3\% isoflurane-induced anesthesia. After the procedure, the mice were monitored for changes in behavior associated with pain or distress, and body weight records were kept. The animals were kept in ventilated cages (up to five mice per cage) in a 12-hour light-dark cycle and were provided water and food ad libitum at all times. The procedures were approved by the Institutional Animal Care and Use Committees at Beth Israel Deaconess Medical Center. Prostates (lateral or ventral lobes) and blood samples were harvested from the different mouse groups at 2 hours, 6 hours, 24 hours, and 3 weeks after injection. The same time points as indicated above were chosen for investigation of the role of carbon monoxide in this model. Animals injected 
with $E$. coli or PBS as well as negative controls inhaled carbon monoxide (250 ppm) for 1 hour, starting 1 hour after injection. The role of myeloid-derived HO-1 in bacteriainduced or sterile prostatitis was investigated by using conditional knockout mice deficient in HO-1 in myeloid cells. These animals were generated by crossing mice with the Hmoxl gene flanked with LoxP sites $\left(H m o x^{f l / f}\right)$ as previously described, ${ }^{30}$ with transgenic mice expressing Cre recombinase under control of the myeloid specific LysM promoter (LysM-Cre) (Jackson Laboratories). LysMCre:Hmox $I^{f / f t}$ and Hmox $I^{f / f t}$ homozygotes with the C57BL/ 6 background were verified by PCR-based genotyping. ${ }^{31}$

\section{Bacteria Stimulation and Carbon Monoxide Treatment of BMDMs in Vitro}

Bone marrow was isolated and prepared as previously described. ${ }^{19}$ Bone marrow-derived macrophages (BMDMs) differentiated in the presence of macrophage-colony-stimulating factor (Prospec, Rehovot, Israel) $(20 \mathrm{ng} / \mathrm{mL})$ for 5 days were scraped off the culture dishes with cell lifters and suspended in fresh RPMI 1640 medium, $10 \%$ fetal bovine serum (FBS), and $1 \%$ penicillinstreptomycin medium (Life Technologies, Carlsbad, CA). The cells were counted and replated in $100-\mathrm{mm}$ dishes $\left(3 \times 10^{6}\right.$ cells per plate). Bacteria (E. coli MG1655) were prepared as described above. Macrophages were washed twice in PBS to remove residual antibiotics and were then stimulated with bacteria (10 multiplicity of infection) for 1 to 2 hours in antibiotic-free culture media. Sterile PBS $(\mathrm{pH}$ 7.4) was added to control plates. Macrophages from stimulated and control groups were treated with carbon monoxide $(250 \mathrm{ppm})$ for 1 hour. Bacteria were removed after 2 hours of stimulation, and medium with antibiotics $(1 \mathrm{~mL}$ medium per 170,000 cells) was added to the plates. Supernatants from the BMDMs were harvested 24 hours after stimulation, filtered, and stored at $-20^{\circ} \mathrm{C}$.

\section{Cell Culture and Soft Agar Colony Assay}

For soft agar colony assay, a base layer of $0.5 \%$ sterile agar RPMI 1640 medium, 10\% FBS, and 1\% penicillin and streptomycin (Life Technologies) was casted into six-well plates, $1 \mathrm{~mL}$ per well, and left to solidify. PC3 and $\mathrm{VCaP}$ prostate cancer cells, previously validated and/or authenticated in Dr. Balk's laboratory, ${ }^{32}$ were used for the study. These cells were grown to $60 \%$ to $80 \%$ confluence in RPMI 1640 medium with $10 \%$ FBS, detached by trypsinization, and diluted to the final concentration of 10,000 cells $/ \mathrm{mL}$ in RPMI 1640 medium, 20\% FBS, and 2\% penicillin and streptomycin. These cell lines were not authenticated in our laboratory but were previously described and characterized. ${ }^{32}$ Each suspension was mixed 1:1 with sterile soft agar $0.7 \%\left(37\right.$ to $39^{\circ} \mathrm{C}$ ) at a final concentration of $0.35 \%$ agar and $10 \%$ FBS, applied to each well on top of the base layer, and left to incubate in the o/n culture. The cells in the soft agar were treated for 2 to 3 weeks with supernatants from differentiated BMDMs treated with bacteria at 10 multiplicity of infection and carbon monoxide (Bacteria Stimulation and Carbon Monoxide Treatment of BMDMs). Medium was changed every third day $(0.5 \mathrm{~mL}$ per well per time). The RPMI 1640 medium with 10\% FBS was used as the negative control.

\section{Measurements of Cell Viability and Proliferation}

PNT1A, VCaP, DU145, and LNCaP cell lines were previously described. ${ }^{33}$ One thousand cells were seeded in 96well plate and treated with supernatants from BMDM treated with E. coli as described above. Viability and proliferation were assessed on day 2 of the culture by staining with crystal violet. Stained and dry cells were dissolved in $10 \%$ acetic acid and processed for measurement of absorbance at $562 \mathrm{~nm}$.

\section{Immunoblotting}

Prostate tissue was sonicated in lysis buffer $(50 \mathrm{mmol} / \mathrm{L}$ Tris chloride, $\mathrm{pH} 7.0,150 \mathrm{mmol} / \mathrm{L}$ sodium chloride, $0.5 \% \mathrm{NP}-$ 40, $2 \mathrm{mmol} / \mathrm{L}$ EDTA, $25 \mathrm{mmol} / \mathrm{L}$ sodium fluoride, $0.1 \%$ SDS, 1 tablet per $10-\mathrm{mL}$ buffer Complete MiniProtease Inhibitor Cocktail; Roche, Indianapolis, IN). The lysates were centrifuged (Microfuge 18 Centrifuge, Beckman Coulter, Bromma, Sweden) for 20 minutes at $18,000 \times \mathrm{g}$, and supernatants were transferred to clean Eppendorf tubes. The centrifugation was repeated once more, and clear supernatants were transferred to new Eppendorf tubes. The protein concentrations in the samples were measured using the Pierce BCA Protein Assay (Thermo Scientific, Waltham, MA), according to the manufacturer's instructions. The samples were adjusted with distilled water to equal concentration. Samples were prepared for electrophoresis by adding $4 \times$ sample buffer (Life Technologies) that contained $10 \% \beta$-mercaptoethanol and boiled for 5 minutes. Samples were loaded (20 to $25 \mu \mathrm{g}$ per well) in NuPAGE Novex $4 \%$ to $12 \%$ Bis-Tris Protein Gels (Life Technologies) using Precision Plus Protein Kaleidoscope (Bio Rad, Hercules, $\mathrm{CA}$ ) as the size marker. Electrophoresis was performed in 2$\mathrm{N}$-morpholino ethanesulfonic acid SDS running buffer (Life Technologies) at 90 to $120 \mathrm{~V}$. Separated proteins were transferred to polyvinylidene difluoride membranes (Amersham, Piscataway, NJ; Bio Rad) in transfer buffer (33 $\mathrm{mmol} / \mathrm{L}$ Tris, $0.19 \mathrm{~mol} / \mathrm{L}$ glycine, and $20 \%$ methanol) at 80 $\mathrm{V}$ for 1.5 hours. Membranes were blocked in $5 \%$ fat-free milk in Tris-buffered saline (TBS) $(50 \mathrm{mmol} / \mathrm{L}$ Tris hydrochloride, $\mathrm{pH} 7.0,150 \mathrm{mmol} / \mathrm{L}$ sodium chloride) for 1 hour in the o/n culture at $+4^{\circ} \mathrm{C}$ followed by incubation with the following primary antibodies: HO-1 1:1000 (ab13248, Abcam, Cambridge, MA), ACSL1 1:1000 (D2H5) (catalog number 9189; Cell Signaling, Beverly, MA), IL-1 $\beta$ 1:500 (ab1413, Millipore, Billerica, MA), phospho-p44/42 MAPK (ERK1/2) (Thr202/Tyr204) 1:1000 (catalog number 9101; 
Cell Signaling), TLR4 1:1000 (ab13556; Abcam), and $\beta$ actin (catalog number A5316; Sigma-Aldrich, St. Louis, MO). After overnight incubation, membranes were washed in $1 \times$ TBS for $2 \times 10$ minutes and then incubated with horseradish peroxidase-conjugated secondary antibodies [anti-mouse $\mathrm{IgG}$, horseradish peroxidase-linked antibody (catalog number 7076; Cell Signaling) or anti-rabbit IgG, horseradish peroxidase-linked antibody (catalog number 7074; Cell Signaling) at 1:5000 dilution for 1 hour at room temperature on orbital shaker, followed by washing twice for 15 minutes in TBS. Proteins were detected on radiofilm after signal development with SuperSignal West Pico Chemiluminescent Substrate and SuperSignal West FemtoChemiluminescent Substrate (Thermo Scientific). Before reprobing with different antibodies, membranes were stripped in ReBlot Plus Strong Antibody Stripping Solution (MilliporeSigma, Burlington, MA) for 10 minutes. Membranes were washed in TBS for 20 minutes and stored until reprobed.

\section{RNA Isolation and Real-Time PCR}

Total RNA was isolated from prostate tissues according to the manufacturer's instructions using an RNeasy MiniRNA Isolation Kit (Qiagen, Germantown, MD). cDNA was synthesized with a iScript cDNA synthesis kit (Bio-Rad) using $1 \mu \mathrm{g}$ isolated RNA following the manufacturer's protocol: $25^{\circ} \mathrm{C}$ for 10 minutes, $37^{\circ} \mathrm{C}$ for 2 hours, and $85^{\circ} \mathrm{C}$ for 5 minutes. Gene expression levels were measured by real-time PCR using SYBR-Green PCR Master Mix (Life Technologies and Applied Biosystems, Foster City, CA) using the following primers: IL-1 $\beta$, forward: 5'-TGGGCCTCAAAGGAAAGA-3', reverse: 5'-GGTGCTGATGTACCAGTT3'; IL-10, forward: 5'-CCAAGCCTTATCGGAAATGA-3', reverse: $5^{\prime}$-TTTTCACAGGGGAGAAATCG-3'; ACSL1: forward: 5'-CTACTACGACCGATGTCAGAACCA-3' reverse: 5'-GGAAATCCACTCATAGGGCTGG-3'; and $\beta$-actin, forward: $5^{\prime}$-TAGACTTCGAGCAGGAGATGGC$3^{\prime}$, reverse: $5^{\prime}$-CCACAGGATTCCATACCCAAGA- $3^{\prime}$. The following program was applied: $95^{\circ} \mathrm{C}$ for 10 minutes, $94^{\circ} \mathrm{C}$ for 30 seconds, $58^{\circ} \mathrm{C}$ for 55 seconds, $72^{\circ} \mathrm{C}$ for 1 minute, $95^{\circ} \mathrm{C}$ for 1 minute, $55^{\circ} \mathrm{C}$ for 30 seconds, and $95^{\circ} \mathrm{C}$ for 30 seconds (step 2 to 4 for 40 cycles). Standard software of Stratagen MxPro 3005P version 4.10 (Agilent Technologies, Santa Clara, CA) was used to measure relative changes in mRNA levels and normalized to the $\beta$-actin levels.

\section{Immunohistochemistry and Immunostaining}

Tissue Fixation and Preparation of Sections

Prostate tissues were fixed in zinc fixative $(0.1 \mathrm{~mol} / \mathrm{L}$ Tris hydrochloride, $0.5 \mathrm{~g} / \mathrm{L}$ of calcium acetate, $5 \mathrm{~g} / \mathrm{L}$ of zinc chloride, and $5 \mathrm{~g} / \mathrm{L}$ of zinc acetate dihydrate) for 48 hours, dehydrated in a series of alcohols with increasing percentages and treated with xylene, and then embedded in paraffin. The paraffin blocks were cut in $5-\mu \mathrm{m}$ sections using microtome and mounted on microscope glass slides (Thermo Scientific). Deparaffinated and rehydrated sections were washed in distilled water three times for 2.5 minutes and placed in PBS ( $\mathrm{pH}$ 7.4) for 5 minutes.

\section{Immunostaining}

Sections were fixed on the slide and antigen retrieved following the optimized protocol for each antibody as specified below [see CD45, phosphorylated histone $\mathrm{H}_{3}$ (p$\mathrm{HH} 3$ ), and HO-1]. After antigen retrieval, sections were washed twice for 5 minutes in PBS and then incubated with 7\% horse serum diluted in PBS for 30 minutes to block unspecific binding. Primary antibodies were applied on each section for overnight incubation at $+4^{\circ} \mathrm{C}$. The following day slides were washed three times in PBS followed by 10 minutes of blocking in $0.5 \%$ hydrogen peroxide solution. After an additional wash in PBS, biotinylated secondary antibodies (Vector Laboratories, Burlingame, CA) were diluted 1:300 in PBS and applied on each section and incubated at room temperature for 1 hour. Slides were washed twice for 5 minutes in $1 \times$ PBS. Avidin-biotin peroxidase complexes were prepared from an $\mathrm{ABC}$ kit (Vectastain, Vector Laboratories) (two drops of A and two drops of B in $10 \mathrm{~mL}$ of PBS) and was let to stabilize at room temperature for 30 minutes and then applied on the slides and incubated at room temperature for 30 minutes. The slides were washed twice for 5 minutes in $1 \times$ PBS before the addition of 3, 3'-diaminobenzidine [ImmPACT DAB peroxidase (HRP) substrate; Vector Laboratories] to develop the staining for 1 to 2 minutes. The color reaction was blocked in distilled water for 5 minutes twice. Nuclei were counterstained with hematoxylin, and the sections were dehydrated in alcohol and xylene and covered in mounting medium and coverslips. The slides were evaluated microscopically (Nikon, Tokyo, Japan), and images were taken at $\times 10$ and $\times 40$ magnification. These antibodies were previously used and verified for specificity by applying IgG negative controls. ${ }^{33}$ Information about staining procedures with specific antibodies is provided below:

\section{Cell Type Markers}

Deparaffinized, rehydrated, and washed sections were cooled in refrigerated PBS $\left(4^{\circ} \mathrm{C}\right)$ for 3 minutes. Antigen retrieval and fixation of tissue were performed by placing the sections in cold acetone with 7\% formalin for 2.5 minutes. The slides were washed in cold PBS for 4 to 5 minutes and then transferred to $1 \times$ PBS at room temperature. The primary antibodies were anti-CD45 antibody (BD Pharmingen, San Diego, CA) 1:50 dilution in PBS, anti-Gr1 (BD Biosciences) 1:50 dilution, anti-F4/80 (BioLegend, San Diego, CA) 1:50 dilution, anti-B220 (BioLegend) 1:50 dilution in PBS, and anti-IL-6 (Abcam) 1:200 dilution. The secondary antibody was biotinylated rabbit anti-rat $\mathrm{IgG}$ (Vector Laboratories) 1:300 dilution in PBS. 


\section{pHH3}

Deparaffinized, rehydrated, and washed sections were fixed in $2 \%$ paraformaldehyde for 3 minutes and washed twice for 5 minutes in PBS. Sections were acidified in $0.1 \mathrm{~mol} / \mathrm{L}$ sodium citrate ( $\mathrm{pH}$ 6.0) for 5 minutes at room temperature and then transferred to warm solution of $0.1 \mathrm{~mol} / \mathrm{L}$ sodium citrate $\left(\mathrm{pH} 6.0,+93^{\circ} \mathrm{C}\right)$ for 25 minutes. The container with hot citrate buffer and the slides were put in an ice water bath for 20 minutes to cool. After antigen retrieval, the slides were placed into PBS at room temperature. The primary antibody was rabbit anti-pHH3 (Ser10) (catalog number 9701; Cell Signaling) 1:100. The secondary antibody was biotinylated goat anti-rabbit IgG (BA-1000, Vector Laboratories).

\section{HO-1}

Fixation and antigen retrieval were performed as above for pHH3 with the exception of warm sodium citrate being applied for 15 minutes. The primary antibodies were rabbit anti-HO-1 (ab13248; Abcam) 1:100, rat anti-mouse CD45 antibody (catalog number 553076; BD Pharmingen), rabbit anti-pHH3 (Ser10; catalog number 9701; Cell Signaling), and rabbit anti-HO-1 antibody (ab13248, Abcam). The secondary antibody was biotinylated goat anti-rabbit IgG (BA-1000; Vector Laboratories).

\section{Immunofluorescence Staining}

Sections were fixed with $2 \%$ paraformaldehyde for $10 \mathrm{mi}-$ nutes after washing with PBS three times and permeabilization with $0.05 \%$ Triton X-100 in PBS for 5 minutes and then washed twice for 5 minutes in $1 \times$ PBS. Horse serum (7\%) diluted in PBS was used for blocking for 30 minutes. The following primary antibodies were applied on each section: ACSL1 (D2H5) rabbit monoclonal antibody (catalog number 9189; Cell Signaling) 1:300 and rat anti-mouse CD45 antibody (catalog number 553076; BD Pharmingen) 1:50. Sections were incubated with primary antibodies overnight at $+4^{\circ} \mathrm{C}$. The following day the slides were placed in PBS twice for 5 minutes and incubated at room temperature in darkness for 1 hour with secondary antibodies diluted 1:300 (anti-rat Alexa Fluor 488 and anti-rabbit Alexa Fluor 594, Life Technologies). Slides were carefully washed with PBS and air-dried followed by covering with Gelvatol (SigmaAldrich). A Zeiss Apotome Axiovert Fluorescence Microscope was used to evaluate the fluorescence staining.

\section{Statistical Analysis}

All values are expressed as means \pm SD. All experiments were performed in duplicates or triplicates and were repeated three times. There were three to six mice in each group. Samples were analyzed using one-way analysis of variance followed by Tukey's multiple comparison test or unpaired $t$-test (two-tailed) for comparison of the two groups. A result was considered significant at $P<0.05$. Analyses were performed using SPPS software version 13.0
(IBM Corp., Armonk, NY) and/or Microsoft Office Excel 2007 (Microsoft Inc., Redmond, WA). All immunohistochemical staining was analyzed in a blinded fashion with at least two researchers (L.V.L., G.C, B.W.) performing image acquisition and analysis.

\section{Results}

This study established a model of mild prostate inflammation by injecting E. coli (nonuropathogenic MG1655 strain) or PBS into the mouse urethra and a bladder via urethral catheter as previously described. ${ }^{34}$ Increased numbers of CD $45^{+}$cells and mitotic cells were found in the prostate after injection of non-uropatogenic MG1655 strain into the mouse urethrea (Figure 1). PBS instillation, which reflects physical injury inflicted by catheterization, injection procedures, or urine reflux, induces sterile inflammation in the prostate and leads to a transient activation of inflammatory responses. .,34 $^{6}$ Prostates from each group of experimental mice were harvested 2, 6, and 24 hours as well as 3 weeks after treatment with a single dose of bacteria or PBS. Within 20 days after infection, no apparent difference was observed in body weights between the groups of mice injected with PBS versus those treated with E. coli (Supplemental Figure S1, A and B).

Specifically, an increased number of $\mathrm{CD} 45^{+}$leukocytes were found in the prostate tissue harvested at 6 hours after instillation of PBS or E. coli, indicative of mild inflammatory reaction in the prostate (Figure 1, A and B). However, infiltration of $\mathrm{CD}_{4} 5^{+}$cells was significantly higher in the prostates harvested from mice injected with $E$. coli compared with the tissue from PBS-treated mice at 24 hours. The number of infiltrating $\mathrm{CD} 45^{+}$cells was elevated in the prostates for up to 3 weeks after a single instillation of E. coli. In this model, positive expression of IL-6, a prototypical inflammatory cytokine, was seen in epithelial and stroma cells in the prostates, which was especially elevated at 3 weeks after injection of E. coli (Supplemental Figure S1C). Upon further analysis, the cell subtypes within the prostates show that $\mathrm{F} 4 / 80^{+}$cells are the major contributors to the $\mathrm{CD}_{4} 5^{+}$population. An increase in number of $\mathrm{F} 4 / 80^{+}$cells in the prostates of mice at 6 hours and 24 hours after PBS treatment as well as 24 hours and 3 weeks in mice injected with $E$. coli was detected (Supplemental Figure S2). Interestingly, there was a $\mathrm{Gr}^{+}$ cell population localized within the vessels in the prostate stroma in mice treated with E. coli for 24 hours (Supplemental Figure S3) unlike in other treatment groups. A minimal contribution of $\mathrm{CD}^{+} \mathrm{T}$ cells to the $\mathrm{CD} 45^{+}$ leukocytes was noted with slight but not significant infiltration into the prostates at 24 hours and 3 weeks (Supplemental Figure S4). For all the above analyses, the spleen was used as a control of positive staining for specific immune cell populations (Supplemental Figures S2-S4). Furthermore, we excluded a contribution of the B cells in prostate inflammation by staining with antibodies against the B220 surface marker (Supplemental Figure S5). 
A

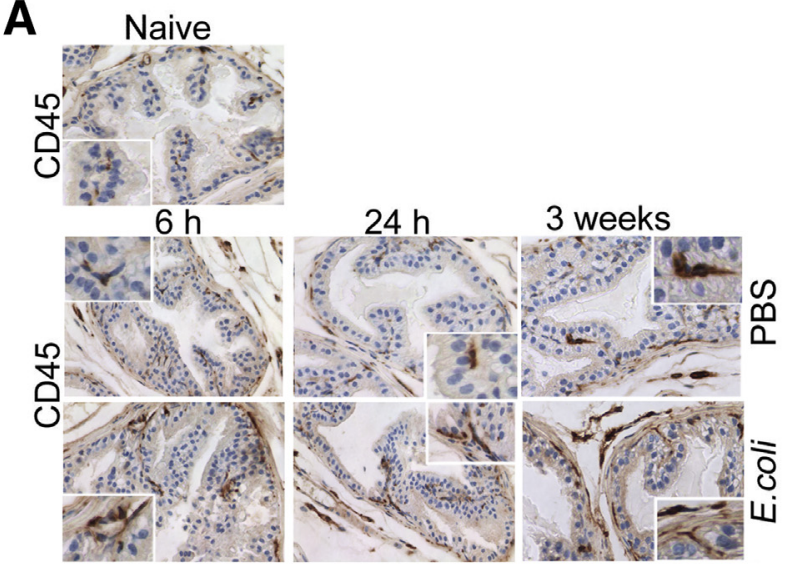

C

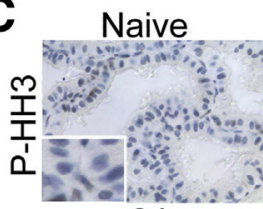

$6 \mathrm{~h}$

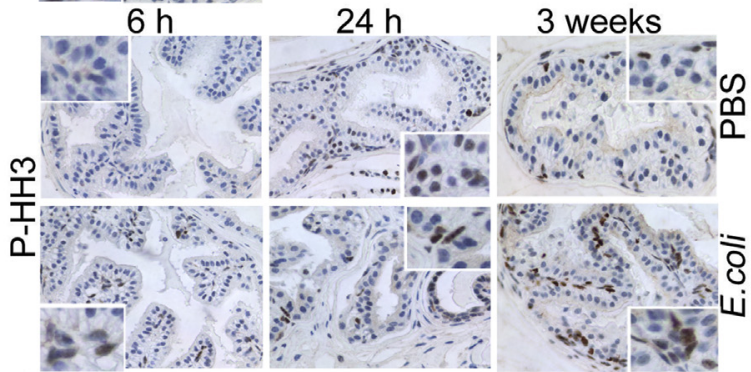

B

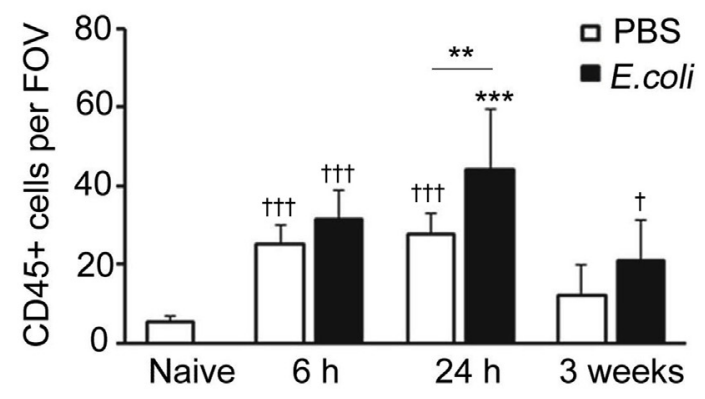

D

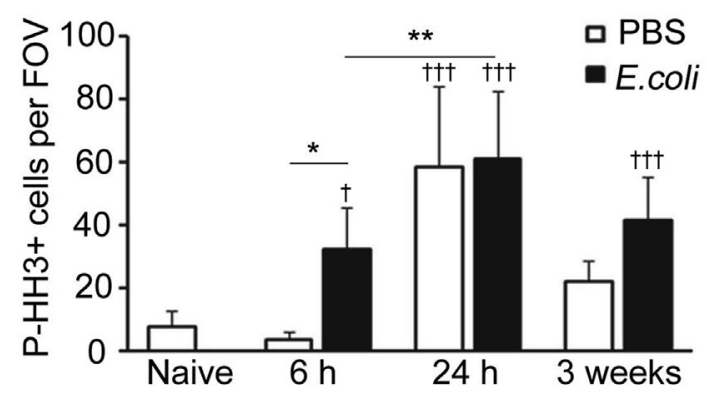

E

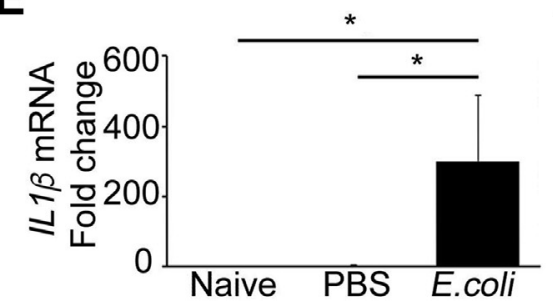

$\mathbf{F}$

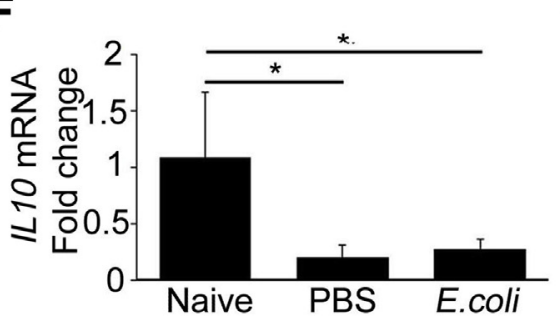

G

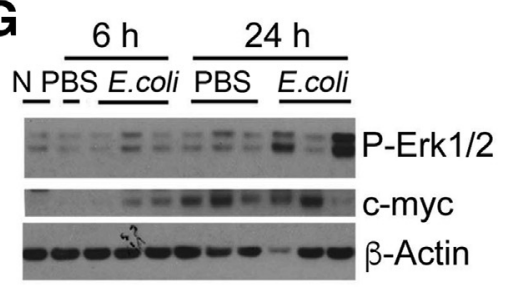

Figure 1 A model of pathogen-induced prostatitis by transurethral instillation of Escherichiascherichia coli in male wild-type mice. A: Immunohistochemistry with antibodies against CD45 (leukocytes) was performed on the prostates harvested 6 hours, 24 hours, and 3 weeks after intraurethral injection of phosphate-buffered saline (PBS) or E. coli $\left[2 \times 10^{8}\right.$ colony-forming units (CFU) per animal]. B: Representative images of $\mathrm{CD}_{4} 5^{+}$cells in prostate presented in A. Insets are shown at higher magnification to better visualize the single cells. Number of CD45 cells per field of view (FOV) in the prostates from mice injected intraurethrally with PBS or E. coli $\left(2 \times 10^{8}\right.$ CFU per animal) at 6 hours, 24 hours, and 3 weeks. C and D: Representative images of phosphorylated histone $\mathrm{H}_{3}^{+}\left(\mathrm{p}-\mathrm{HH}^{+}\right)$cells in prostate after 6 hours, 24 hours, and 3 weeks in mice treated as in $\mathbf{A}$. Insets are shown at higher magnification to better visualize the single cells. Number of $\mathrm{p}-\mathrm{HH}^{+}$cells per FOV in prostate from mice as described in $\mathbf{D}$. $\mathbf{E}$ and $\mathbf{F}$ : mRNA expression of cytokines interleukin 1 beta (IL1B) (E) and interleukin 10 (IL10) (F) presented as a fold change in PBS or E. coli injected mice $\left(2 \times 10^{8}\right.$ CFU per animal) versus naive controls (value normalized to 2 hours after injection). G: Immunoblot of phospho-ERK1/2 and CMyc in prostate lysates from mice 6 hours and 24 hours after intraurethral injection of PBS or $E$. coli $\left(2 \times 10^{8}\right.$ CFU per animal). Data are expressed as means \pm SD (B, D, E, and $\left.\mathbf{F}\right) . n=3$ individuals per group (B); $n=3$ to 4 animals per group (E and $\left.\mathbf{F}\right)$. ${ }^{*} P<0.05,{ }^{* *} P<0.01 ;{ }^{\dagger} P<0.05,{ }^{\dagger \dagger \dagger} P<0.001$ versus naive. Original magnification: $\times 200$ (A and $\mathbf{C}$, main images); 400 (A and $\mathbf{C}$, insets). $\mathrm{N}$, naive.

Next, proliferative responses in the prostates harvested from control and bacteria-infected mice were evaluated. The levels of p-HH3, an established marker of cell proliferation, were mildly elevated in the prostates after $E$. coli instillation as early as 6 hours after treatment and remained elevated at 24 hours and 3 weeks (Figure 1, C and D). Mice injected with PBS also showed a significant increase in p-HH3 staining in the prostates at 24 hours after injection compared with naive mice; however, no difference between naive or mice injected with PBS was detected at 6 hours or 3 weeks (Figure 1, C and D). These data suggest a mild proliferative and inflammatory response in the prostate upon intraurethral instillation of bacteria or PBS.

In the groups of mice injected with E. coli, a marked increase in IL1 $\beta$ mRNA levels in the prostate was noticed (Figure 1E). In contrast, expression of IL10, 
an anti-inflammatory cytokine, was inhibited by instillation of $E$. coli or $\mathrm{PBS}$ compared with naive mice (Figure 1F).

Because increased p-HH3 was observed in our model, the phosphorylation status of MAPK ERK1/2 and the level of c-myc were evaluated. It was found that induction of phosphorylated MAPK ERK1/2 and increased expression of c-myc at 6 and 24 hours after injections of PBS or E. coli (Figure $1 \mathrm{G}$ ) were indicative of heighten proliferation status of the cells in these prostates.

A

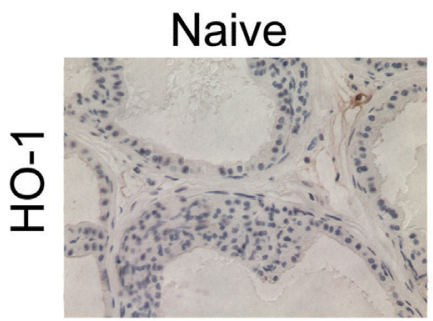

B

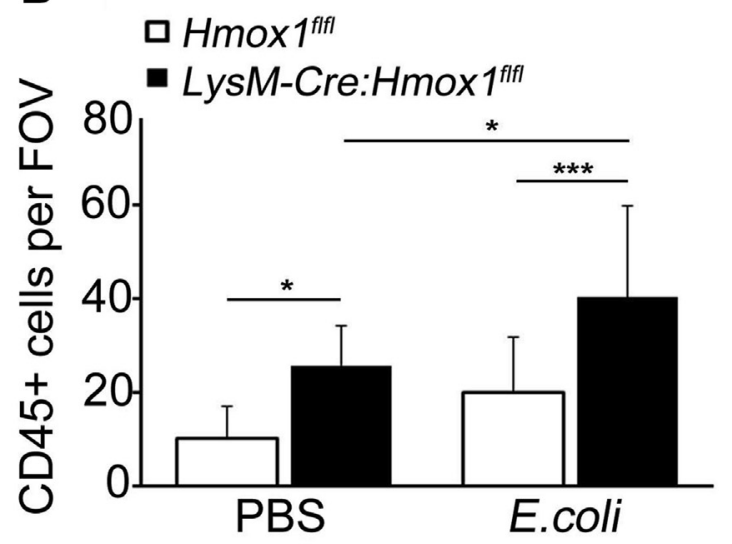

D

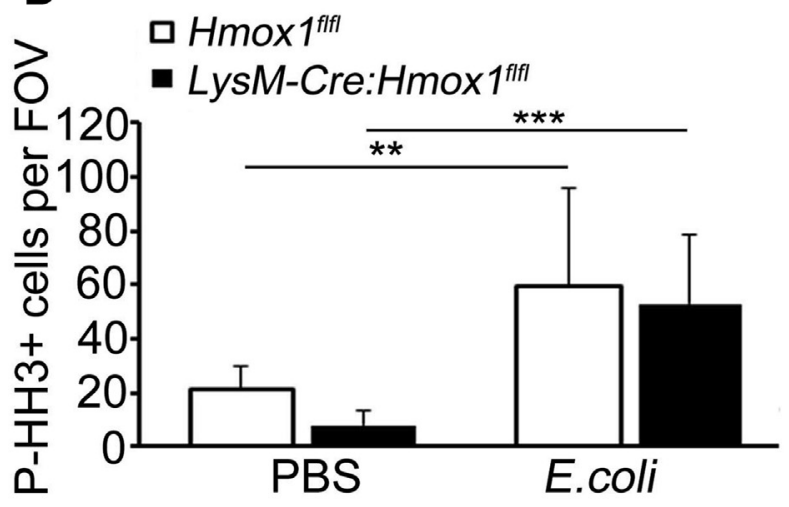

3 weeks

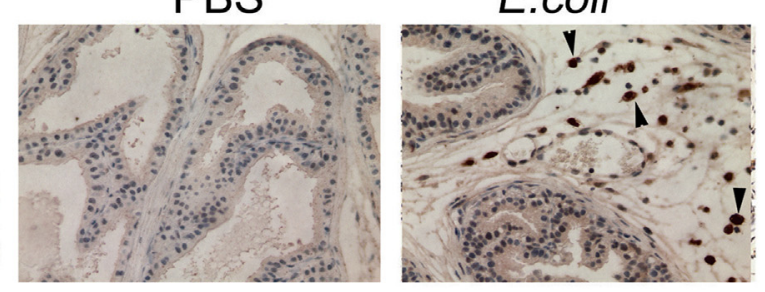

C

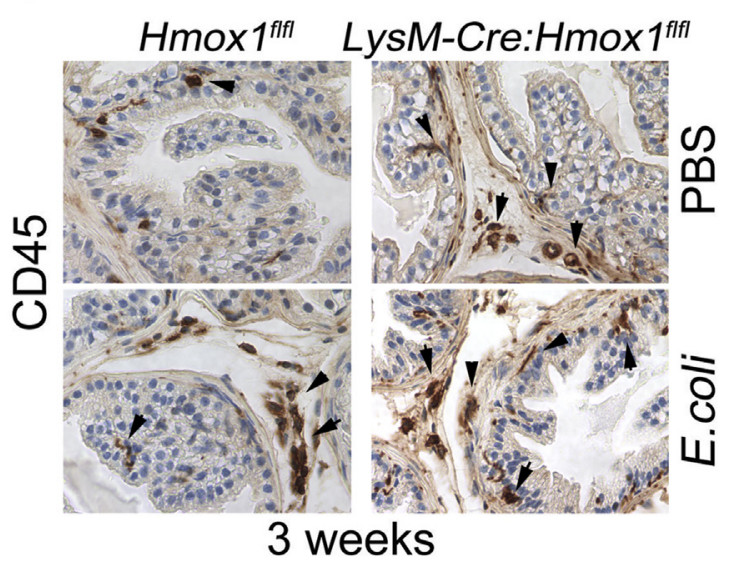

$\mathbf{E}$

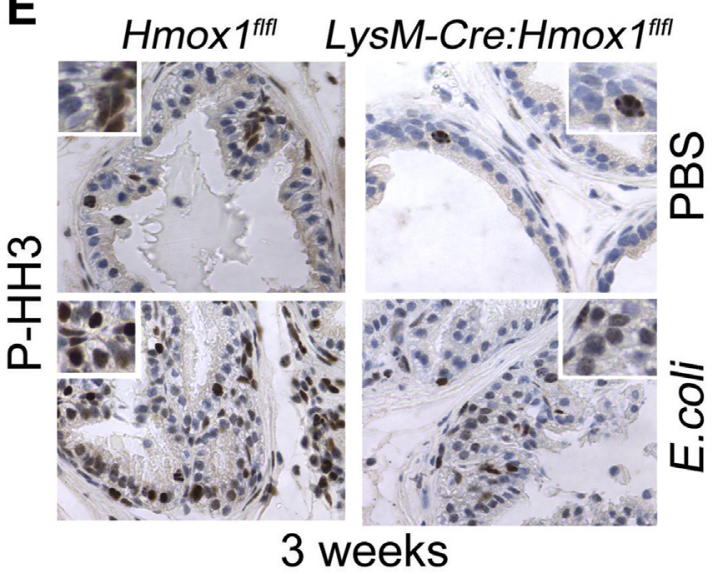

Figure 2 A role of myeloid-derived heme oxygenase 1 (HMOX1; H0-1) in a model of prostate inflammation. A: Representative immunohistochemical staining of $\mathrm{HO}-1$ in prostate tissue harvested 3 weeks after induction of prostatitis, performed as in Figure 1. Arrows indicate stained cells. B and C: Quantification and representative images of $\mathrm{CD}_{4} 5^{+}$cells in prostates from conditional myeloid-specific H0-1 knockout mice (LysM-Cre:Hmox $1^{f / f l}$ ) compared with $H \operatorname{mox} 1^{f l / f l}$ (wild-type) mice 3 weeks after phosphate-buffered saline (PBS) or Escherichia coli intraurethral injection $\left[2 \times 10^{8}\right.$ colony-forming units (CFU) per animal]. Arrows indicate stained cells. Number of CD45 cells per field of view (FOV) in prostate 3 weeks after intraurethral injection of PBS or $E$. coli in $H \operatorname{mox} 1^{f l f l}$ versus $L y s M-C r e: H \operatorname{mox} 1^{f l f l}$ mice are shown in B. D and E: Quantification and representative images of phosphorylated -histone $\mathrm{H}_{3}^{+}\left(\mathrm{p}-\mathrm{HH} 3^{+}\right) \mathrm{Cells}$ in $H \operatorname{mox} 1^{f l f l}$ versus conditional LysM-Cre:Hmox $1^{f l f l}$ mice treated as in $\mathbf{B}$. Number of $\mathrm{p}-\mathrm{HH}^{+}$cells per FOV in mice prostates is shown (D). Representative images of $\mathrm{p}-\mathrm{HH} 3$ staining in mice $(\mathbf{E})$. Insets are shown at higher magnification to better visualize the single cells. Data are expressed as means \pm SD (B and $\mathbf{D}) . n=2$ to 3 animals per group. ${ }^{*} P<0.05,{ }^{* *} P<0.01$, and ${ }^{* *} P<0.001$. Original magnification, $\times 200(\mathbf{A}, \mathbf{C}$, and $\mathbf{E}) ; \times 400$ (insets). 
A

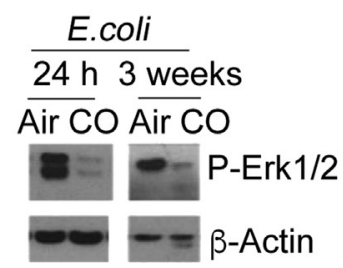

D

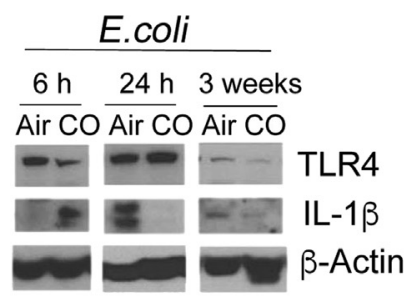

B

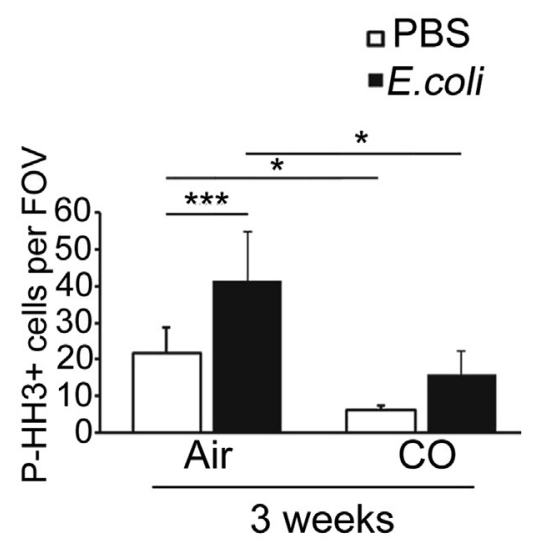

E
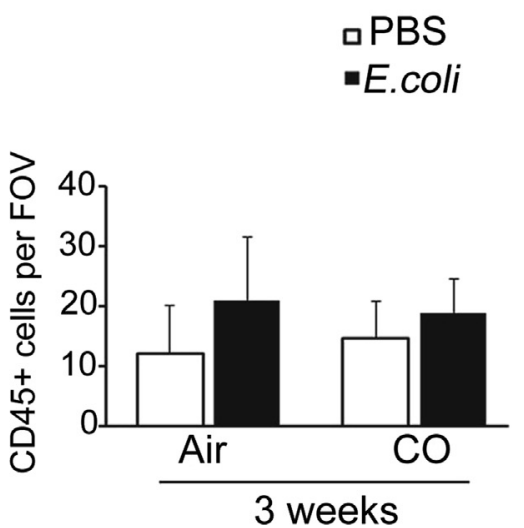

C

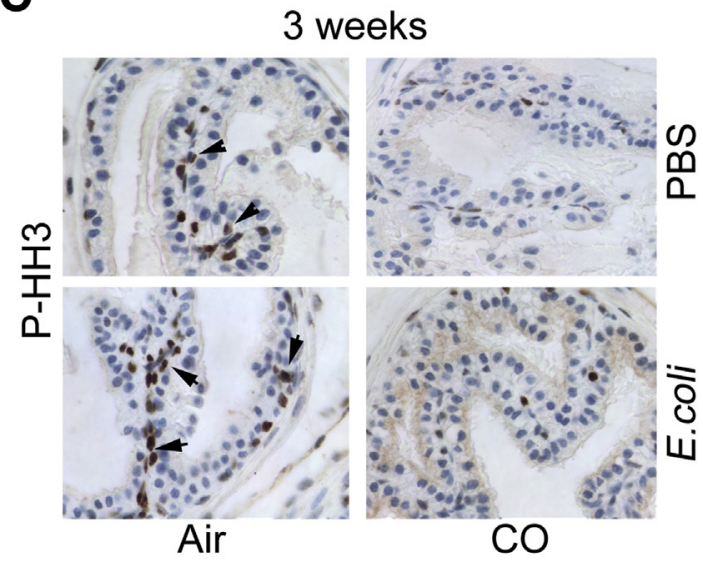

$\mathbf{F}$

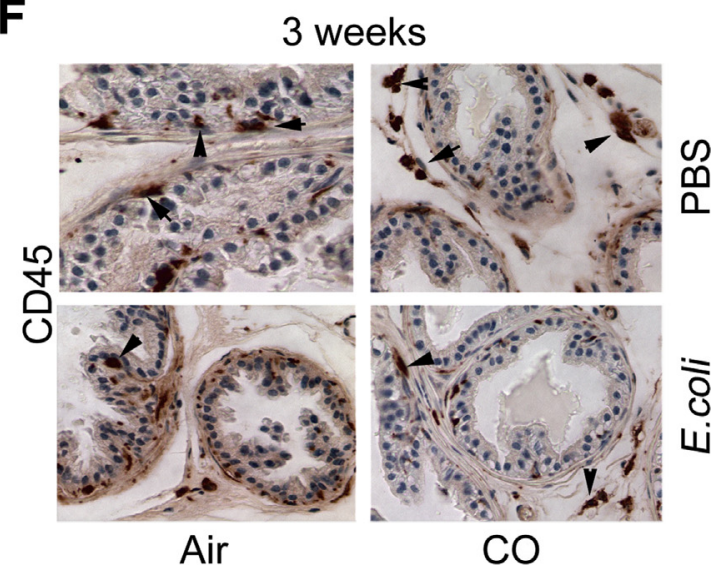

Figure 3 A role of carbon monoxide treatment on inflammation and proliferation in prostatitis. A: Immunoblot with antibodies against phosphorylated ERK1/2 (p-ERK1/2) in prostate from wild-type mice injected intraurethrally with Escherichia coli [2 $\times 10^{8}$ colony-forming units (CFU) per animal]. Mice treated with carbon monoxide starting 1 hour after infection ( $250 \mathrm{ppm}$ for 1 hour) were compared with controls kept in air 24 hours and 3 weeks after instillation of bacteria. B and C: Number of phosphorylated histone $\mathrm{H}_{3}^{+}\left(\mathrm{p}-\mathrm{HH}^{+}\right)$cells in prostate 3 weeks after injection of phosphate-buffered saline (PBS) or $E$. coli $\left(2 \times 10^{8}\right.$ CFU per animal) followed by carbon monoxide treatment as described in A. Representative images of p-HH3 staining presented in C. D: Immunoblot of IL-1 $\beta$ (pro-form at $40 \mathrm{kDa}$ ) and toll-like receptor 4 (TLR4) in air versus carbon monoxide treated mice as described in A 6 hours after E. coli or PBS intraurethral injection. $\mathbf{E}$ and $\mathbf{F}$ : Immunohistochemistry with antibodies against CD45. Quantification of CD45 ${ }^{+}$cells in prostate is shown in E. F: Representative images or $\mathrm{CD}_{4} 5^{+}$cells shown in $\mathbf{F}$. Arrows indicate cells positive for $\mathrm{p}-\mathrm{HH} 3$ staining. Data are expressed as means $\pm \mathrm{SD} .{ }^{*} P<0.05,{ }^{* * *} P<0.001$. 0riginal magnification, $\times 400(\mathbf{C}$ and $\mathbf{F})$.

H0-1 Is Induced by E. coli Treatment and Mitigates Infiltration of Leukocytes into the Prostate

To dissect the role of the heme degradation pathway in the chronic prostatitis model, HO-1 levels were first measured in the prostates. An increased number of $\mathrm{HO}-1^{+}$cells in the stroma in the prostates of mice instilled with E. coli was observed (Figure 2A). These HO- $1^{+}$cells likely correspond to the inflammatory cells. ${ }^{19}$ To assess the role of HO-1 in infiltrating myeloid cells, a conditional knockout mice model lacking HO-1 in myeloid cells (LysM-Cre:Hmox $I^{f / f}$ ) was used. The frequency of $\mathrm{CD} 45^{+}$and $\mathrm{p}-\mathrm{HH}^{+}$cells was compared in the groups of LysM-Cre:Hmoxl $I^{f / f l}$ and Hmox $I^{f / f l}$ littermate controls, 3 weeks after a challenge with bacteria or PBS (Figure 2, B-E). Although the infiltration of $\mathrm{CD}_{4} 5^{+}$cells was augmented in LysM-Cre:Hmoxf $f^{f / f t}$ mice, compared with Hmoxl $I^{f / f l}$ mice in both PBS- and E. coli-injected groups (Figure 2, B and C), the number of p- $\mathrm{HH}^{+}$cells was independent of the presence of HO-1 in myeloid cells (Figure 2, D and E).

These results suggest that HO-1 expressed by myeloid cells suppresses infiltration of $\mathrm{CD} 45^{+}$cells into the prostate stroma after E. coli infection. These cells are likely to be primarily myeloid cells.

\section{CO Suppresses Mitosis in the Prostate and Modulates Inflammatory Processes after Bacterial Infection without Reducing the Number of Infiltrating Leukocytes}

Carbon monoxide is a product of HO-1 activity that mimics many if not all effects of HO-1. Furthermore, exogenous carbon monoxide increases macrophage functionality in clearing bacteria by driving activation of the Nalp3 inflammasome-dependent IL-1 $\beta$ processing. ${ }^{19}$ In this 
A

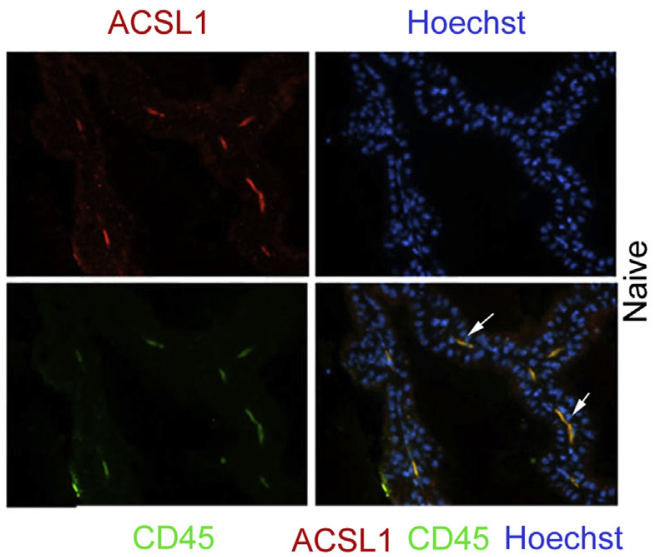

B
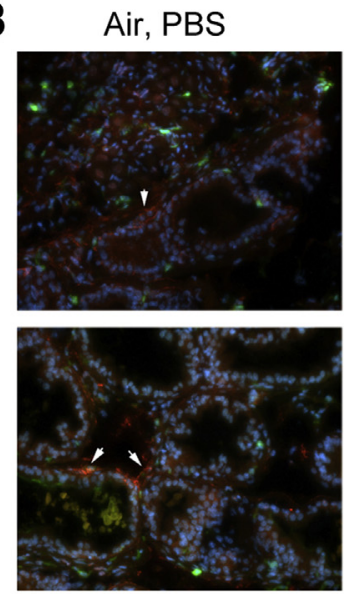

CO, PBS
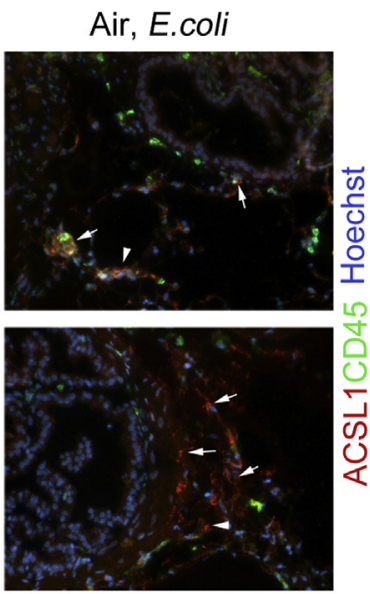

CO, E.coli
C

$$
\frac{2 \mathrm{~h}}{\text { PBS E.coli }}
$$

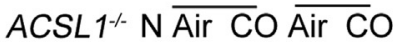

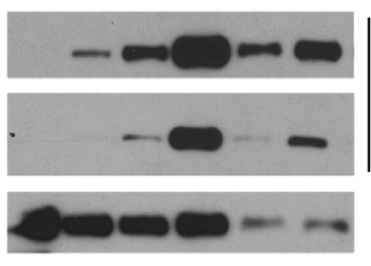

D

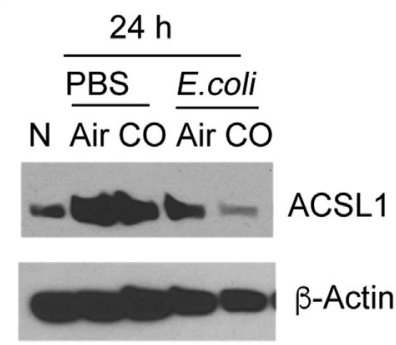

E

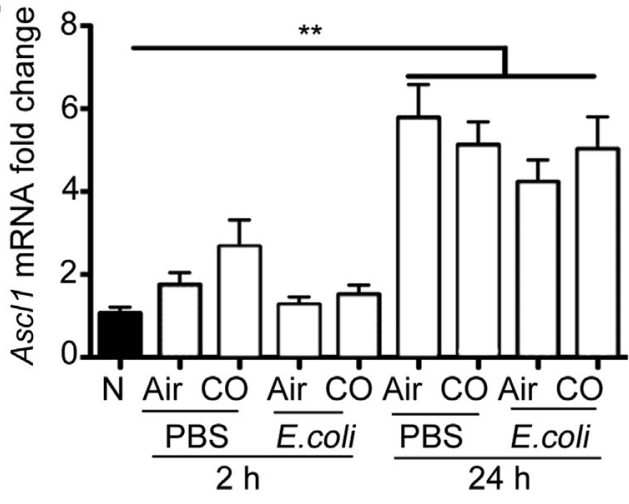

$\mathbf{F}$

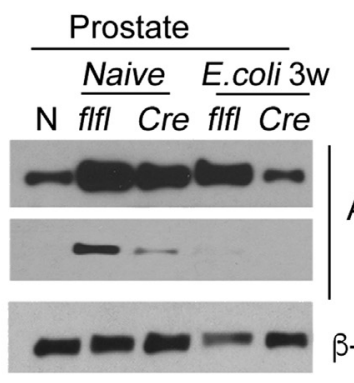

G

ACSL1

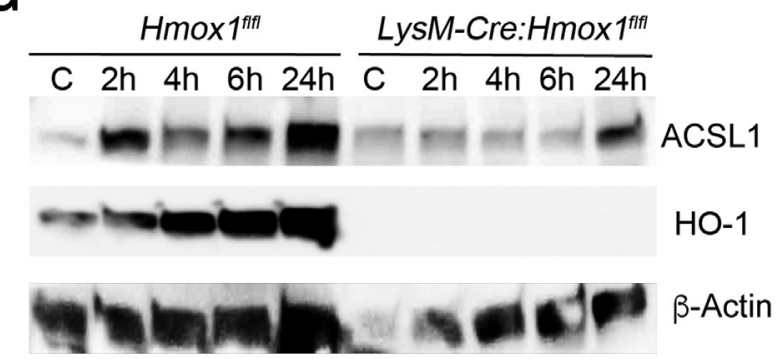

Figure 4 Role of lipid metabolic enzyme long-chain acyl-CoA synthetase 1 (ACSL1) in carbon monoxide-mediated effects during inflammation of the prostate. A and B: Immunofluorescence co-staining of ACSL1 and CD45 in prostate from naive control (A) and from phosphate-buffered saline (PBS)- or Escherichia coli-injected animals after 24 hours (B). Arrows and arrowheads indicate positive cells. C and D: Immunoblotting of ACSL1 in prostate lysates from PBS- or $E$. coli-injected mice $\left(2 \times 10^{8}\right.$ CFU per animal) with or without carbon monoxide (1 hour, 250 ppm starting 1 hour after injection) harvested directly after treatment at 2 or 24 hours. Lysates of bone marrow-derived macrophages (BMDMs) from LysM-Cre:Acsl1 $1^{f f l}$ mice treated with $E$. coli were used as an antibody specificity control for the Western blot. E: Real-time PCR using primers against Acsl1 in the samples of mRNA isolated from the prostates of mice treated as in C and D. F: Immunoblotting of ACSL1 in prostate lysates from LysM-Cre:Hmox $1^{\text {flfl }}$ or Hmox $1^{f f l}$ (flfl) mice injected with PBS or E. coli (2 $\times 10^{8}$ CFU per animal) and harvested 3 weeks after injection. G: Immunoblotting with antibodies against ACSL1 in the lysates of BMDMs isolated from Hmox ${ }^{f f l}$ and $L y s M$ Cre:Hmox $1^{f f l}$ mice and treated with E. coli for 2 hours. After 2 hours of incubation of BMDMs with bacteria, media were changed, antibiotics were added, and lysates were harvested 2 to 24 hours later. Data are expressed as means $\pm S D(E) . n=4$ per group $(\mathbf{C}$ and $\mathbf{D}) ; n=3$ to 4 per group $(\mathbf{E}) ; n=3$ independent experiments $(\mathbf{G}) .{ }^{* *} P<0.01$. Original magnification, $\times 200(\mathbf{A}$ and $\mathbf{B}) . \mathbf{N}$, naive wild-type control.

model of prostatitis, carbon monoxide decreases phosphorylated MAPK ERK1/2 levels in the prostate lysates in the group of mice treated with E. coli (Figure 3A). Moreover, fewer mitotic cells (p-HH3) in the prostates isolated from carbon monoxide-treated mice were detected at 3 weeks after injection of PBS or E. coli (Figure 3, B and C). At early time points, carbon monoxide upregulated IL-1 $\beta$ that could explain early and effective resolution of inflammation, leading to suppression of chronic proliferative responses after carbon monoxide treatment (Figure 3D). Indeed, carbon monoxide treatment inhibited IL- $1 \beta$ expression at later time points, suggesting suppression of chronic inflammation. Carbon monoxide treatment did not alter TLR4 expression levels (Figure 3D) or the number of infiltrating 

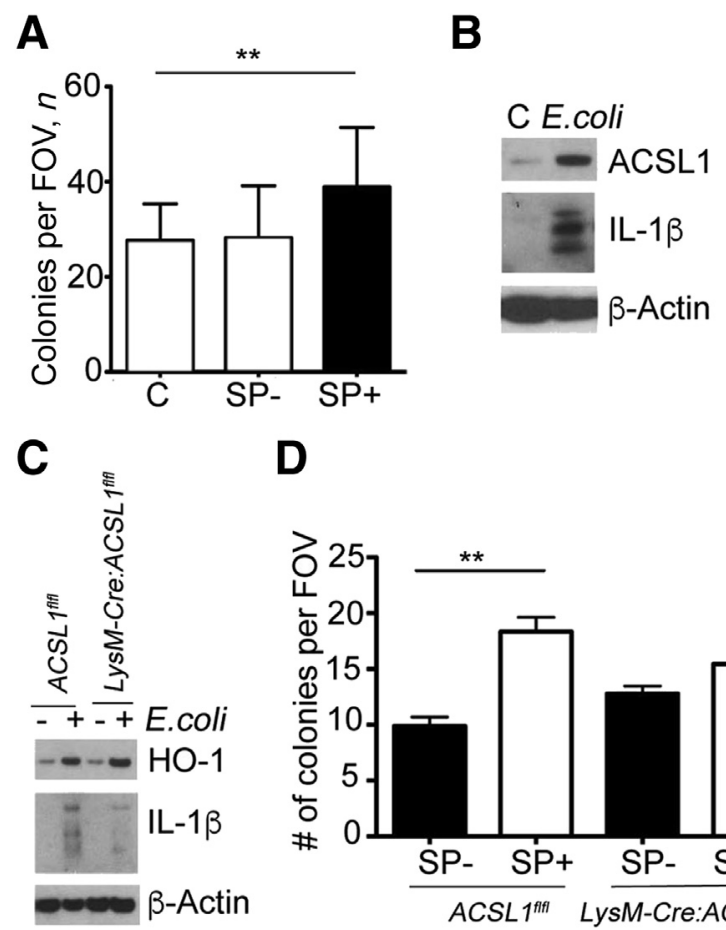

D

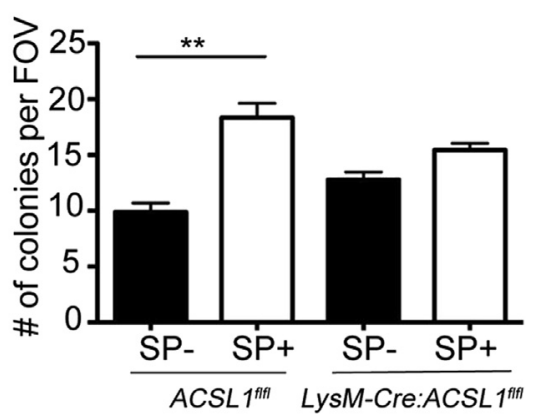

Figure 5 Role of long-chain acyl-CoA synthetase 1 (ACSL1) in macrophages during bacterial infection. A: Quantification of number of PC3 colonies in soft agar after treatment with supernatant from bone marrow-derived macrophages (BMDMs) treated with live Escherichia coli (10 multiplicity of infection for 2 hours) or $80 \mu \mathrm{L}$ of sterile phosphate-buffered saline (PBS). After 1 hour of incubation of BMDMs with bacteria, media were changed, antibiotics were added, and supernatants were harvested 24 hours later. Supernatants were filtered and used to treat PC 3 cells grown in soft agar. Three weeks after treatment, colonies were counted. B and C: Western blotting with antibodies against IL-1 $\beta$ in the lysates of BMDMs from wild-type (B) or LysM-Cre control and LysM-Cre:Acslfifl $(L y s M-C r e)$ mice (C) treated with live $E$. coli (10 multiplicity of infection for 2 hours). After 2 hours of incubation of BMDMs with bacteria, media were changed, antibiotics were added, and supernatants were harvested 24 hours later as in $\mathbf{A}$. D: $\mathrm{PC} 3$ cells were grown in the soft agar with medium from $E$. coli-treated BMDMs from LysM-Cre control or LysM-Cre:Acsl1 ${ }^{f f l}$ (LysM-Cre) mice as in A. Data are expressed as means \pm SD (A and $\mathbf{D}) . n=3$ independent experiments. ${ }^{* * P}<0.01$. C, control; $\mathrm{SP}-$, supernatant from control macrophages; $\mathrm{SP}+$, supernatant from macrophages treated with $E$. coli.

$\mathrm{CD} 45^{+}$cells in the prostate (Figure 3, E and F). These data highlight the cellular activation status, which, as opposed to the number of infiltrating cells, might explain the effects of carbon monoxide.

The Fatty Acid Metabolic Enzyme ACSL1 Is Induced by Inflammation and Regulated by $\mathrm{H} 0-1$ and/or Carbon Monoxide in the Prostate

ACSL1 regulates immune responses of myeloid cells by allowing acyl-CoA formation and phospholipid remodeling after cellular activation by cytokines or lipopolysaccharide. ${ }^{28,29}$ Interestingly, positive staining of ACSL1 was noted in $\mathrm{CD}_{4} 5^{+}$leukocytes in the prostate and PBS- or E. coli-treated prostates (Figure 4, A and B). Indeed, increased levels of ACSL1 were detected in the lysates of the prostates from mice treated with $E$. coli at 24 hours (Supplemental Figure S6). Therefore, it was investigated whether ACSL1 may crosstalk with the HO-1 pathway to affect inflammatory responses during prostatitis. Early induction of ACSL1 was observed at the protein level in the prostates of mice treated with carbon monoxide and PBS or $E$. coli at 2 hours (Figure 4C), which was no longer evident at 24 hours (Figure 4D). Acsll mRNA levels in the prostate did not change significantly, but a slight induction of ACSL1 was observed after carbon monoxide treatment at 2 hours (Figure 4E), corresponding to the protein level (Figure 4C). Acsll mRNA levels increased significantly at 24 hours.

Also, HO-1 expressed in myeloid cells regulates ACSL1 expression in response to $E$. coli (Figure 4F). Lower protein levels of ACSL1 in mice whose myeloid cells lack HO-1 were detected at the baseline level and after bacteria treatment (Figure 4F). Higher expression levels of ACSL1 were observed along with HO-1 induction in response to $E$. coli treatment at 2 hours up to 24 hours in wild-type BMDMs (Figure 4G). There was a significant delay in the induction of ACSL1 in response to E. coli in BMDMs isolated from HO-1-deficient mouse (Figure 4G). These data indicate a possible regulation of ACSL1 via HO-1 and carbon monoxide in myeloid cells in the prostate.

\section{Myeloid Cell-Expressed ACSL1 Regulates IL-1 $\beta$ Production in Response to $E$. coli}

To assess the role of ACSL1 in controlling macrophage function in the prostate microenvironment, we used models of prostate cancer and transformed prostate epithelial cell lines cultured in the presence of supernatants derived from macrophage cultures. Supernatants collected from macrophages treated with $E$. coli had higher efficacy to promote anchor-independent growth of PC3 prostate cancer cells in soft agar compared with supernatants collected from unchallenged macrophages (Figure 5A). The same conditions improved the survival of transformed prostate epithelial cell line PNT1A (Supplemental Figure S7A) and prostate cancer cell lines (DU145, PC3) (Supplemental Figure S7, B and C). No difference was found in the viability or proliferation of $\mathrm{LNCaP}$ or $\mathrm{VCaP}$ cell lines in the presence of supernatants from macrophages treated with E. coli (Supplemental Figure S7, D and E).

ACSL1 and IL-1 $\beta$ along with HO-1 were induced in response to E. coli treatment in BMDMs (Figure 5, B and C). Importantly, lack of ACSL1 in macrophages led to lower IL-1 $\beta$ production in response to $E$. coli infection in vitro (Figure $5 \mathrm{C}$ ), indicating that ACSL1 expression in macrophages in the prostate might be a critical mediator of inflammatory responses. Furthermore, supernatants collected from Acsll-deficient macrophages treated with $E$. coli had lower efficacy to induce PC 3 colony growth in vitro (Figure 5D). These data suggest that ACSL1 may play an important role in controlling inflammation in the prostate as a target of HO-1/carbon monoxide pathway. 


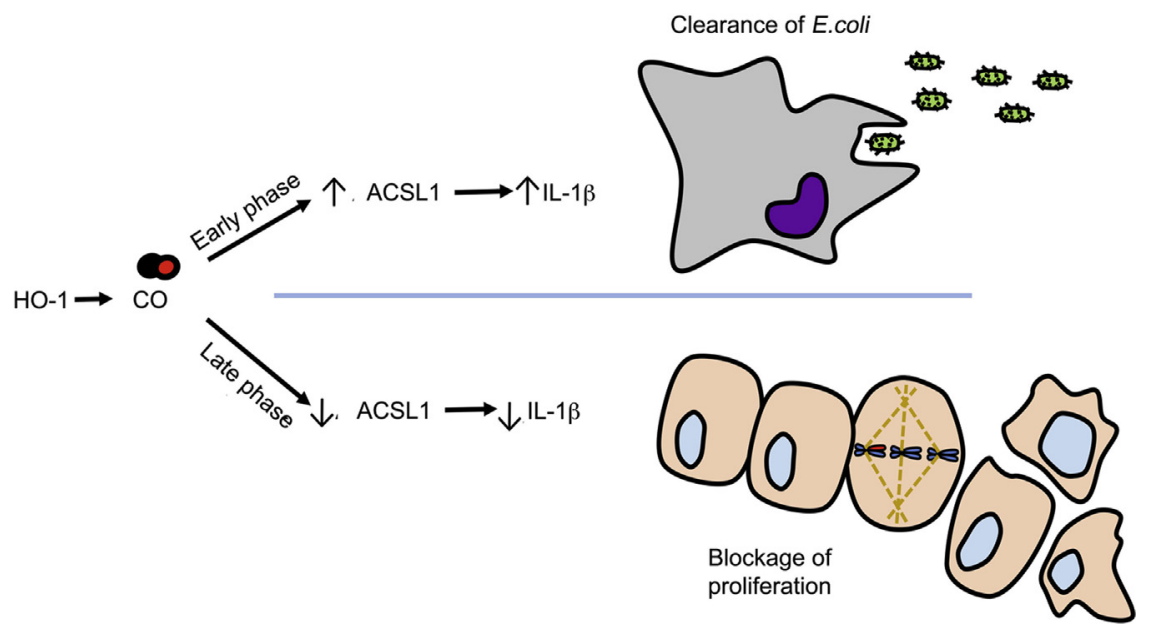

Figure 6 Scheme indicating the early and late phase effects of heme oxygenase 1 (HMOX1; H0-1 and/or carbon monoxide on inflammatory responses in the bacteria-infected prostate. ACSL1, long-chain acyl-CoA synthetase 1 .

\section{Discussion}

This study found that HO-1 and/or carbon monoxide modulates inflammation in the prostate in part via a novel ACSL1-IL-1 $\beta$ pathway in myeloid cells (Figure 6). Urinary tract infections are common in humans, leading to pain and potentially an increased risk of prostate inflammation as well as prostate cancer. Understanding the mechanisms of sterile and pathogen-driven inflammatory responses in the prostate may help to prevent long-term changes in the prostate gland and carcinogenesis.

It was observed that the acute inflammatory processes caused by bacteria may lead to long-lasting changes in prostate proliferation and inflammation. Our model using a non-uropathogenic strain of $E$. coli led to mild inflammation with an increase primarily in myeloid cells. Mice injected with PBS also showed signs of inflammation in the prostates; however, the immune response was transient and was not significantly different from that of naive controls at 3 weeks time point. In contrast, in E. coli-treated mice, the number of $\mathrm{CD} 45^{+}$cells remained elevated at 3 weeks after treament. The transient inflammatory response to PBS injection is in agreement with the observation of Kwon et al, ${ }^{34}$ where intraurethral injection of PBS led to a physical injury as a result of urine reflux and increased pressure in the prostate. Recent data suggest that urine reflux to the prostate causes sterile prostatitis. ${ }^{35}$ This, however, may be shortlasting and resolved, unless it is accompanied by bacteria infection. Our data clearly indicate that chronic inflammation is primarily induced by pathogen infection to the prostate.

Heighten meta-inflammation is correlated with low levels of HO-1 in patients with metabolic syndrome and in patients with moderate to severe lower urinary tract symptoms secondary to benign prostatic hyperplasia. ${ }^{36} \mathrm{HO}-1$ and the products of heme degradation have anti-inflammatory or proinflammatory effects, depending on the time of their induction or administration. ${ }^{37-40}$ In this study, HO- 1-positive myeloid cells show immunosuppressive phenotype and are likely to contribute to the anti-inflammatory responses in the prostate. Previous work has demonstrated that HO-1 deficiency leads to poorer expansion and differentiation of myeloid cells toward macrophages, including a pool of F4/80 macrophages. ${ }^{30}$ Therefore, macrophages lacking $\mathrm{HO}-1$ in the prostate might be less mature and inefficient in removal of bacteria and/or cellular debris. Indeed, it was previously shown that HO-1 in macrophages supports a better bacteria clearance. ${ }^{19}$

Akin to HO-1, carbon monoxide promotes cell proliferation and regeneration of injured tissues. ${ }^{41,42}$ Carbon monoxide treatment inhibited cellular proliferation but did not affect the number of $\mathrm{CD} 45^{+}$cells after intraurethral bacteria or PBS instillation in the mouse prostate. The differential effect of HO-1 and/or carbon monoxide might be due to the generation of heme degradation products other than carbon monoxide, such as biliverdin, bilirubin, or iron, and their contribution to the effects seen in the prostate. Moreover, these data indicate that modulation of inflammatory cell infiltration and cell proliferation in the prostate might be two independent processes. The role of carbon monoxide might be to restore homeostasis through suppressing proliferation and therefore to prevent development of hyperplasia and sequential prostatic intraepithelial neoplasia lesions. Indeed, carbon monoxide blocked prostatic intraepithelial neoplasia development and inhibited the growth of prostate cancer in a spontaneous model of prostate cancer (TRAMP mice). ${ }^{33}$ Interestingly, exogenous carbon monoxide induced early release of the proinflammatory cytokine IL-1 $\beta$. It was previously reported that carbon monoxide acts directly on bacteria to release ATP and activate Nalp3 inflammasome-mediated IL-1 $\beta$ secretion from macrophages infected with bacteria. ${ }^{19}$ At later time points, suppression of IL-1 $\beta$ is likely a consequence of the faster removal of bacteria or anti-inflammatory effect of carbon monoxide. A decrease in IL-1 $\beta$ levels in response to carbon monoxide may impact its effects on cell proliferation in the 
prostate. Similar observations were made in IL-1R knockout mice. ${ }^{26}$ In the infammed prostate, proliferation of c-kit+ progenitor cells was suppressed in IL-1R knockout mice. ${ }^{26}$ Interestingly, unchanged numbers of infiltrating leukocyte into the inflamed prostate were seen in the same IL-1R knockout mice, akin to that observed after carbon monoxide treatment.

ACSL1 regulates macrophage function and controls inflammation in diabetic mice ${ }^{29}$ and in prostate cancer. ${ }^{27}$ Another ACSL isoform, ACSL3, has been implicated in regulation of prostate cancer progression via control of steroidogenesis. ${ }^{43}$ In normal, non-inflamed tissue, ACSL1 was almost specifically expressed in $\mathrm{CD} 45^{+}$leukocytes, indicating a potential role of this enzyme in residential tissue macrophages. Carbon monoxide treatment led to increased protein expression of ACSL1 in the prostates collected from mice challenged in PBS- or E. coli-induced prostatitis models at early time points. The later decrease in the expression of ACSL1 in the presence of carbon monoxide was similar to the IL-1 $\beta$ regulation and is likely due to modulation of myeloid cell phenotype. This finding indicates that carbon monoxide might regulate inflammatory responses, at least in part, through ACSL1. We speculate that HO-1 and/or carbon monoxide may promote fatty acid synthesis and lipid metabolism, which are deployed for diverse anabolic processes in macrophages and epithelial cells in response to bacterial infection or sterile inflammation. It was previously found that carbon monoxide targets glucose metabolism in cancer cells to suppress their proliferation. ${ }^{33}$

Remarkably, supernatants from macrophage cultures treated with bacteria promoted viability of cancer cell lines (PC3 and DU145) as well as transformed epithelial cells PNT1A. Interestingly, two androgen-sensitive cell lines, $\mathrm{VCaP}$ and $\mathrm{LNCaP}$, did not respond to the same stimuli, suggesting a possible specificity between the inflammatory stimuli and the androgen receptor signaling. ${ }^{44-47}$ Diminished PC3 prostate cancer growth was observed in soft agar in response to supernatant collected from E. coli-treated macrophages with deletion of ACSL1, suggesting that ACSL1-driven soluble factors are likely responsible for cell proliferation. These factors secreted from bacteriastimulated macrophages will be a focus of our future work. Similar effects were previously noted in a model of pancreatic cancer in which proinflammatory macrophages potently induced epithelial to mesenchymal transition in cancer cells. ${ }^{48}$ It is possible that switches in heme and lipid metabolism in immune cells influence inflammation and cytokine release that are known to promote cellular transformation in the prostate. ${ }^{34}$

In summary, our results suggest that HO-1 and/or CO has a regulatory function in a model of bacterial infection and/or sterile inflammation in the prostate. Additional studies warrant investigation on the role of HO-1 in specific cell types and, its impact on inflammatory mediators and proliferative responses in epithelial cells in the inflamed prostate. Furthermore, it would be of interest to assess the role of
HO-1 and/or CO in a uropathogenic model of bacteria infection in the prostate or other models of prostatitis. We provide the first evidence that carbon monoxide treatment might have beneficial effects by blocking inflammation and proliferation in the prostate acting in part via a novel ACSL1-IL-1 $\beta$ signaling pathway.

\section{Acknowledgment}

We thank Dr. Steven Balk for helpful discussion of the project and for providing prostate cancer cell lines.

\section{Author Contributions}

L.V.L. designed and performed all in vivo experiments and drafted the manuscript; E.C. helped and performed multiple immunohistochemical experimentation; A.H., A.K., G.C., and M.L. participated in acquisition of in vitro data and immunohistochemical analysis; F.K. helped with experiments using myeloid-targeted Acsll-deficient mice; K.E.B. provided myeloid-targeted Acsll-deficient mice, helped with study design using Acsll-deficient mice, interpretation of the data, and editing of the manuscript; B.W. designed, performed experiments, analyzed, and supervised the studies; all authors read and revised the manuscript, and meet all four criteria for authorship.

\section{Supplemental Data}

Supplemental material for this article can be found at http://doi.org/10.1016/j.ajpath.2019.12.008.

\section{References}

1. Schatteman PH, Hoekx L, Wyndaele JJ, Jeuris W, Van Marck E: Inflammation in prostate biopsies of men without prostatic malignancy or clinical prostatitis: correlation with total serum PSA and PSA density. Eur Urol 2000, 37:404-412

2. Delongchamps NB, de la Roza G, Chandan V, Jones R, Sunheimer R, Threatte G, Jumbelic M, Haas GP: Evaluation of prostatitis in autopsied prostates-is chronic inflammation more associated with benign prostatic hyperplasia or cancer? J Urol 2008, 179:1736-1740

3. Roberts RO, Bergstralh EJ, Bass SE, Lieber MM, Jacobsen SJ: Prostatitis as a risk factor for prostate cancer. Epidemiology 2004, 15: 93-99

4. Dennis LK, Lynch CF, Torner JC: Epidemiologic association between prostatitis and prostate cancer. Urology 2002, 60:78-83

5. Hua VN, Williams DH, Schaeffer AJ: Role of bacteria in chronic prostatitis/chronic pelvic pain syndrome. Curr Urol Rep 2005, 6: 300-306

6. Boehm BJ, Colopy SA, Jerde TJ, Loftus CJ, Bushman W: Acute bacterial inflammation of the mouse prostate. Prostate 2012, 72: 307-317

7. Funahashi Y, Wang Z, O'Malley KJ, Tyagi P, DeFranco DB, Gingrich JR, Takahashi R, Majima T, Gotoh M, Yoshimura N: Influence of E. coli-induced prostatic inflammation on expression of androgen-responsive genes and transforming growth factor beta 1 cascade genes in rats. Prostate 2015, 75:381-389 
8. Liu Y-C, Zou X-B, Chai Y-F, Yao Y-M: Macrophage polarization in inflammatory diseases. Int J Biol Sci 2014, 10:520-529

9. Coussens LM, Werb Z: Inflammation and cancer. Nature 2002, 420: $860-867$

10. Mantovani A, Allavena P, Sica A, Balkwill F: Cancer-related inflammation. Nature 2008, 454:436-444

11. Elkahwaji JE, Hauke RJ, Brawner CM: Chronic bacterial inflammation induces prostatic intraepithelial neoplasia in mouse prostate. Br J Cancer 2009, 101:1740-1748

12. Dos Santos Gomes FO, Oliveira AC, Ribeiro EL, da Silva BS, Dos Santos LAM, de Lima IT, Silva A, da Rocha Araujo SM, Goncalves T, de Melo-Junior MR, Peixoto CA: Intraurethral injection with LPS: an effective experimental model of prostatic inflammation. Inflamm Res 2018, 67:43-55

13. Tenhunen R, Marver HS, Schmid R: The enzymatic conversion of heme to bilirubin by microsomal heme oxygenase. Proc Natl Acad Sci U S A 1968, 61:748-755

14. Tenhunen R, Marver HS, Schmid R: Microsomal heme oxygenase: characterization of the enzyme. J Biol Chem 1969, 244:6388-6394

15. Naito $Y$, Takagi T, Higashimura $Y$ : Heme oxygenase-1 and antiinflammatory M2 macrophages. Arch Biochem Biophys 2014, 564: $83-88$

16. Otterbein LE, Soares MP, Yamashita K, Bach FH: Heme oxygenase1: unleashing the protective properties of heme. Trends Immunol 2003, 24:449-455

17. Wegiel B, Hanto DW, Otterbein LE: The social network of carbon monoxide in medicine. Trends Mol Med 2013, 19:3-11

18. Otterbein LE, May A, Chin BY: Carbon monoxide increases macrophage bacterial clearance through Toll-like receptor (TLR)4 expression. Cell Mol Biol (Noisy-le-grand) 2005, 51:433-440

19. Wegiel B, Larsen R, Gallo D, Chin BY, Harris C, Mannam P, Kaczmarek E, Lee PJ, Zuckerbraun BS, Flavell R, Soares MP, Otterbein LE: Macrophages sense and kill bacteria through carbon monoxide-dependent inflammasome activation. J Clin Invest 2014, 124:4926-4940

20. Ayna G, Krysko DV, Kaczmarek A, Petrovski G, Vandenabeele P, Fesus L: ATP release from dying autophagic cells and their phagocytosis are crucial for inflammasome activation in macrophages. PLoS One 2012, 7:e40069

21. Bours MJ, Dagnelie PC, Giuliani AL, Wesselius A, Di Virgilio F: P2 receptors and extracellular ATP: a novel homeostatic pathway in inflammation. Front Biosci (Schol Ed) 2011, 3:1443-1456

22. Jalilian I, Peranec M, Curtis BL, Seavers A, Spildrejorde M, Sluyter V, Sluyter R: Activation of the damage-associated molecular pattern receptor $\mathrm{P} 2 \mathrm{X} 7$ induces interleukin-1beta release from canine monocytes. Vet Immunol Immunopathol 2012, 149:86-91

23. Petrovski G, Ayna G, Majai G, Hodrea J, Benko S, Madi A, Fesus L: Phagocytosis of cells dying through autophagy induces inflammasome activation and IL-1beta release in human macrophages. Autophagy 2011, 7:321-330

24. Culig Z, Hobisch A, Herold M, Hittmair A, Thurnher M, Eder IE, Cronauer MV, Rieser C, Ramoner R, Bartsch G, Klocker H, Konwalinka G: Interleukin 1beta mediates the modulatory effects of monocytes on LNCaP human prostate cancer cells. Br J Cancer 1998, 78:1004-1011

25. Liu Q, Russell MR, Shahriari K, Jernigan DL, Lioni MI, Garcia FU, Fatatis A: Interleukin-1beta promotes skeletal colonization and progression of metastatic prostate cancer cells with neuroendocrine features. Cancer Res 2013, 73:3297-3305

26. Wang L, Zoetemelk M, Chitteti BR, Ratliff TL, Myers JD, Srour EF, Broxmeyer H, Jerde TJ: Expansion of prostate epithelial progenitor cells after inflammation of the mouse prostate. Am J Physiol Renal Physiol 2015, 308:F1421-F1430

27. Wu X, Daniels G, Lee P, Monaco ME: Lipid metabolism in prostate cancer. Am J Clin Exp Urol 2014, 2:111-120

28. Rubinow KB, Wall VZ, Nelson J, Mar D, Bomsztyk K, Askari B, Lai MA, Smith KD, Han MS, Vivekanandan-Giri A, Pennathur S,
Albert CJ, Ford DA, Davis RJ, Bornfeldt KE: Acyl-CoA synthetase 1 is induced by Gram-negative bacteria and lipopolysaccharide and is required for phospholipid turnover in stimulated macrophages. J Biol Chem 2013, 288:9957-9970

29. Kanter JE, Kramer F, Barnhart S, Averill MM, Vivekanandan-Giri A, Vickery T, Li LO, Becker L, Yuan W, Chait A, Braun KR, PotterPerigo S, Sanda S, Wight TN, Pennathur S, Serhan CN, Heinecke JW, Coleman RA, Bornfeldt KE: Diabetes promotes an inflammatory macrophage phenotype and atherosclerosis through acyl-CoA synthetase 1. Proc Natl Acad Sci U S A 2012, 109:E715-E724

30. Wegiel B, Hedblom A, Li M, Gallo D, Csizmadia E, Harris C, Nemeth Z, Zuckerbraun BS, Soares M, Persson JL, Otterbein LE: Heme oxygenase-1 derived carbon monoxide permits maturation of myeloid cells. Cell Death Dis 2014, 5:e1139

31. Mamiya T, Katsuoka F, Hirayama A, Nakajima O, Kobayashi A, Maher JM, Matsui H, Hyodo I, Yamamoto M, Hosoya T: Hepatocyte-specific deletion of heme oxygenase-1 disrupts redox homeostasis in basal and oxidative environments. Tohoku J Exp Med 2008, 216:331-339

32. Yu Z, Cai C, Gao S, Simon NI, Shen HC, Balk SP: Galeterone prevents androgen receptor binding to chromatin and enhances degradation of mutant androgen receptor. Clin Cancer Res 2014, 20: 4075-4085

33. Wegiel B, Gallo D, Csizmadia E, Harris C, Belcher J, Vercellotti GM, Penacho N, Seth P, Sukhatme V, Ahmed A, Pandolfi PP, Helczynski L, Bjartell A, Persson JL, Otterbein LE: Carbon monoxide expedites metabolic exhaustion to inhibit tumor growth. Cancer Res 2013, 73:7009-7021

34. Kwon OJ, Zhang L, Ittmann MM, Xin L: Prostatic inflammation enhances basal-to-luminal differentiation and accelerates initiation of prostate cancer with a basal cell origin. Proc Natl Acad Sci U S A 2014, 111:E592-E600

35. Funahashi Y, Majima T, Matsukawa Y, Yamamoto T, Yoshida M, Gotoh M: Intraprostatic reflux of urine induces inflammation in a rat. Prostate 2017, 77:164-172

36. Russo GI, Vanella L, Castelli T, Cimino S, Reale G, Urzi D, Li Volti G, Gacci M, Carini M, Motta F, Caltabiano R, Puzzo L, Sorrenti V, Morgia G: Heme oxygenase levels and metaflammation in benign prostatic hyperplasia patients. World J Urol 2016, 34:1183-1192

37. Chauveau C, Remy S, Royer PJ, Hill M, Tanguy-Royer S, Hubert FX, Tesson L, Brion R, Beriou G, Gregoire M, Josien R, Cuturi MC, Anegon I: Heme oxygenase-1 expression inhibits dendritic cell maturation and proinflammatory function but conserves IL10 expression. Blood 2005, 106:1694-1702

38. Listopad J, Asadullah K, Sievers C, Ritter T, Meisel C, Sabat R, Docke WD: Heme oxygenase-1 inhibits $\mathrm{T}$ cell-dependent skin inflammation and differentiation and function of antigen-presenting cells. Exp Dermatol 2007, 16:661-670

39. Schumacher A, Wafula PO, Teles A, El-Mousleh T, Linzke N, Zenclussen ML, Langwisch S, Heinze K, Wollenberg I, Casalis PA, Volk HD, Fest S, Zenclussen AC: Blockage of heme oxygenase-1 abrogates the protective effect of regulatory $\mathrm{T}$ cells on murine pregnancy and promotes the maturation of dendritic cells. PLoS One 2012, 7:e42301

40. Xia ZW, Xu LQ, Zhong WW, Wei JJ, Li NL, Shao J, Li YZ, Yu SC, Zhang ZL: Heme oxygenase-1 attenuates ovalbumin-induced airway inflammation by up-regulation of foxp3 T-regulatory cells, interleukin-10, and membrane-bound transforming growth factor- 1 . Am J Pathol 2007, 171:1904-1914

41. Hanto DW, Maki T, Yoon MH, Csizmadia E, Chin BY, Gallo D, Konduru B, Kuramitsu K, Smith NR, Berssenbrugge A, Attanasio C, Thomas M, Wegiel B, Otterbein LE: Intraoperative administration of inhaled carbon monoxide reduces delayed graft function in kidney allografts in swine. Am J Transplant 2010, 10: $2421-2430$

42. Nakao A, Kimizuka K, Stolz DB, Neto JS, Kaizu T, Choi AM, Uchiyama T, Zuckerbraun BS, Nalesnik MA, Otterbein LE, 
Murase N: Carbon monoxide inhalation protects rat intestinal grafts from ischemia/reperfusion injury. Am J Pathol 2003, 163:1587-1598

43. Migita T, Takayama KI, Urano T, Obinata D, Ikeda K, Soga T, Takahashi S, Inoue S: ACSL3 promotes intratumoral steroidogenesis in prostate cancer cells. Cancer Sci 2017, 108:2011-2021

44. Izumi K, Li L, Chang C: Androgen receptor and immune inflammation in benign prostatic hyperplasia and prostate cancer. Clin Investig (Lond) 2014, 4:935-950

45. Quintar AA, Maldonado CA: Androgen regulation of host defenses and response to inflammatory stimuli in the prostate gland. Cell Biol Int 2017, 41:1223-1233

46. Debelec-Butuner B, Alapinar C, Varisli L, Erbaykent-Tepedelen B, Hamid SM, Gonen-Korkmaz C, Korkmaz KS: Inflammation- mediated abrogation of androgen signaling: an in vitro model of prostate cell inflammation. Mol Carcinog 2014, 53:85-97

47. Vignozzi L, Cellai I, Santi R, Lombardelli L, Morelli A, Comeglio P, Filippi S, Logiodice F, Carini M, Nesi G, Gacci M, Piccinni MP, Adorini L, Maggi M: Antiinflammatory effect of androgen receptor activation in human benign prostatic hyperplasia cells. J Endocrinol 2012, 214:31-43

48. Helm O, Held-Feindt J, Grage-Griebenow E, Reiling $\mathrm{N}$, Ungefroren H, Vogel I, Kruger U, Becker T, Ebsen M, Rocken C, Kabelitz D, Schafer H, Sebens S: Tumor-associated macrophages exhibit pro- and anti-inflammatory properties by which they impact on pancreatic tumorigenesis. Int J Cancer 2014, 135: $843-861$ 